\title{
COMPARATIVE EVALUATION OF PRESSURE DISTRIBUTION BETWEEN HORIZONTAL AND VERTICAL WELLS IN A RESERVOIR (EDGE WATER DRIVE)
}

\author{
I. Eiroboyi ${ }^{1, *}$ and S. I. Wilkie ${ }^{2}$ \\ 1DEPARTMENT OF PETROLEUM ENGINEERING, IGBINEDION UNIVERSITY, OKADA, EDO STATE. NIGERIA

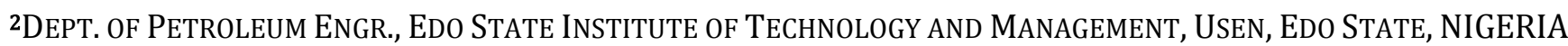 \\ E-mail addresses:1ebitoh@yahoo.com, 2 ameewilkie@yahoo.com
}

\begin{abstract}
This paper presents comparative analysis between the pressure behavior of a horizontal well and a vertical well both subject to edge water drive. Green and source function were used to evaluate the performance of horizontal well and vertical well, eventually, compared based dimensionless pressures and pressure derivatives computed by varying the reservoir geometry. Results presented as type curves show that the rate of decline of the pressure derivative curve is more sharper and sensitive in vertical well than horizontal well of the same geometry indicating a shorter period of clean oil production in vertical well than the horizontal well. The period of radial flow as shown by the horizontal flattened part of the type curve indicate that for all reservoir geometry, the horizontal well will be able to sustain longer period of the radial flow than vertical well given infinite conductivity condition.
\end{abstract}

Keywords: dimensionless pressure, dimensionless pressure derivative, horizontal well, vertical well, edge water drive, radial flow

\section{INTRODUCTION}

Pressure behaviour of a horizontal well is considerably more complicated than it is for vertical wells because of the potential occurrence of several transient flow periods. This paper carries out a comparative study between a horizontal well and a vertical well model both subject to edge water drive to determine the pressure differences and significant characteristics between the two. Both early and late flow periods were considered for both models of negligible skin and wellbore storage influences. Source and green function are used in deriving the appropriate dimensionless pressure expression for both reservoir systems.

The use of dimensionless pressure and dimensionless pressure derivative type curves has fully overcome the challenges experienced in the use of conventional methods and has brought about major successes in well tests analysis. Heterogeneities hardly visible on the conventional plot of well testing data are amplified on the derivative plot, also flow regimes have clear characteristic shapes using the derivative plot [1]. Also to confirm or validate the results of conventional straight line methods like drawdown etc., thus it can be used when the straight line methods cannot adequately characterize the reservoir [2]. When a reservoir is bounded by water influx, information such as pressure distribution, are important in determining wellbore pressure regimes and allowable rate profiles to guarantee clean oil [3]. Musk at and Coats studied vertical well performance in a reservoir with bottom water drive. Musk at utilized potential theory to study the performance of reservoir subject to bottom water and concluded that bottom hole pressures and withdrawal rates are directly responsible for water breakthrough and quality of oil produced [4]. Coats studied vertical well performance in a reservoir with bottom water drive. [5]. Muskat's study, using flow potential distribution, predated the use of source and Green's functions suggested by Gringarten and Ramey. In the Gringarten et al [6] approach, once the reservoir boundaries are identified, a vertical well flow is duplicated by a 2D multiplication of the characteristic functions and a 3D multiplication for horizontal well flow, in accordance with Newman product rule. Ozkan [7] produced dimension pressures derivative for a horizontal well subject to bottom water drive. Adewole [8] also use source and green functions to derive different dimensionless pressure and pressure derivatives for different direction of flow in an A shaped architecture experiencing bottom water, he concluded that individual layer characterization requires properties from only the layer involved, while extended reservoir 
characterization requires equivalent (total layers) properties. and Eiroboyi [9] developed type curves for a reservoir with bottom water drive using source and green functions,

\section{MODEL DESCRIPTION}

Chosen for this study as can be seen below are 2 models, figure 1 is a horizontal well completion while figure 2 is a vertical well completion, and both subjected to edge water drive, also containing oil of small and constant compressibility. Two flow periods are considered (early radial and final flow). Tarek gives the approximate period of radial flow in vertical wells as 10-6 $\leq t D_{e} \leq$ $0.25 r e D^{2}$. This implies that aftertimet $D_{e} \geq 0.25 r e D^{2}$ radial flow ends and the reservoir external boundary effects.

\subsection{Source Functions}

Instantaneous source or Green's functions are selected based on the type of boundary condition according to Gringarten et al [6]

\subsubsection{Horizontal Well Flow Model}

Along the $\mathrm{x}$ - axis, according to Gringarten et al, the source is an infinite plane source in an infinite in an infinite slab source:

Also, along the $\mathrm{y}-$ axis

$$
s\left(x_{D}, t_{D}\right)=\frac{2}{x e_{D}} \sum_{n=1}^{\infty} \exp \left(-\frac{(2 n+1)^{2} \pi^{2} t_{D}}{4 x e_{D}^{2}}\right) \cos \frac{(2 n+1) \pi x w_{D}}{x e_{D}} \cos \frac{(2 n+1) \pi x_{D}}{x e_{D}}
$$

$$
s\left(y_{D}, t_{D}\right)=\frac{1}{y e_{D}}\left[1+2 \sum_{n=1}^{\infty} \exp \left(-\frac{n^{2} \pi^{2} t_{D}}{y e_{D}^{2}}\right) \cos \frac{n \pi y w_{D}}{y e_{D}} \cos \frac{n \pi y_{D}}{y e_{D}}\right]
$$

$\mathrm{Z}$ - axis

$$
s\left(z_{D}, t_{D}\right)=\frac{1}{h_{D}}\left[1+2 \sum_{n=1}^{\infty} \exp \left(-\frac{l^{2} \pi^{2} t_{D}}{h_{D}^{2}}\right) \sin \frac{l \pi z w_{D}}{h_{D}} \sin \frac{l \pi z_{D}}{h_{D}}\right.
$$

\subsubsection{Vertical Well Flow}

Along the $\mathrm{x}$ - axis, the reservoir is experiencing edge water as such giving a constant recharge to the system, the source is an infinite plane source in an infinite slab reservoir.

While along the $\mathrm{y}$ - axis,

$$
S\left(x_{D}, t_{D}\right)=\frac{2}{x e} \sum_{n=1}^{\infty} \exp \left(-\frac{(2 n+1)^{2} \pi^{2} \mathrm{t}_{\mathrm{D}}}{4 X e^{2}}\right) \cos \frac{(2 \mathrm{n}+1) \pi X w}{X e} \cos \frac{(2 n+1) \pi X}{X e}
$$

$$
S\left(y_{D}, t_{D}\right)=\frac{1}{y e}\left[1+2 \sum_{n=1}^{\infty} \exp \left(\frac{-n^{2} \pi^{2} t_{D}}{y e^{2}}\right) \sin \frac{n \pi y w}{y e} \sin \frac{n \pi y}{y e}\right]
$$
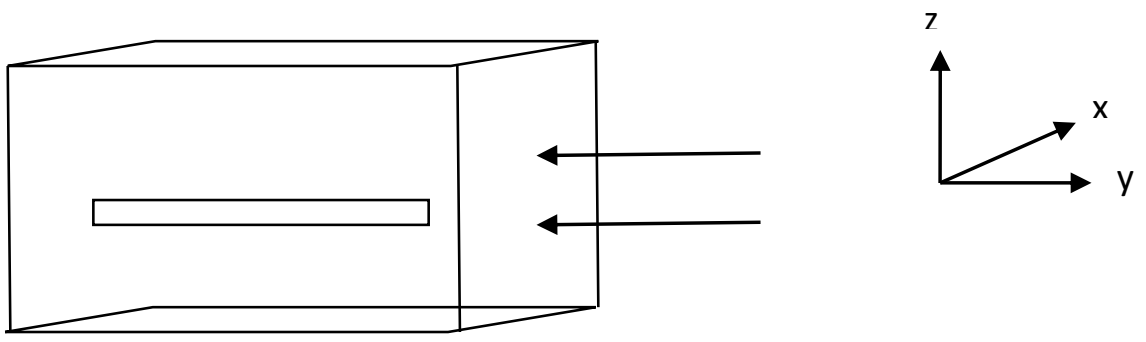

Figure 1: Horizontal well model in a reservoir subject to edge water
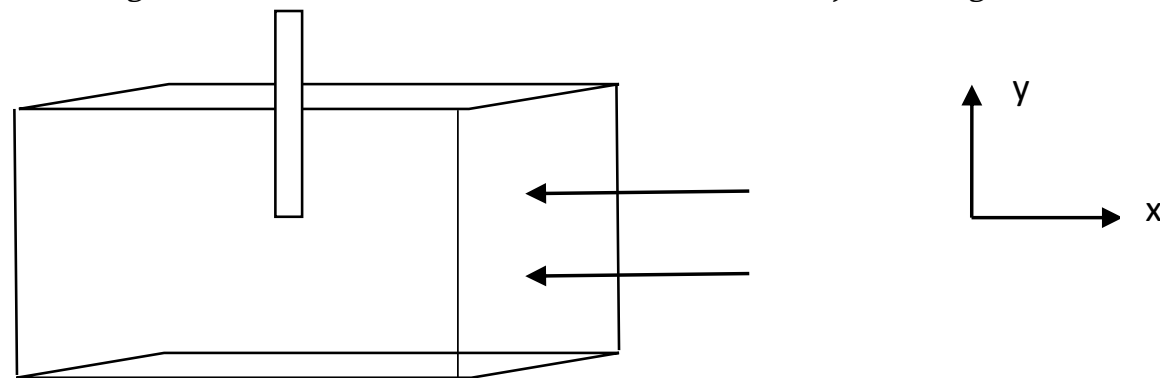

Figure 2: Vertical well model in a reservoir subject to edge water 
2.2 Derivation of Dimensionless Pressure and Dimensionless Pressure Derivative Expressions 2.2.1 Horizontal Well Model

For a single layer reservoir,

$$
\begin{aligned}
& p_{D}=2 \pi h_{D} \int_{0}^{t_{D}} s\left(x_{D}, \tau\right) \cdot s\left(y_{D}, \tau\right) \cdot s\left(z_{D}, \tau\right) \\
& p_{D}=-\frac{\alpha h_{D}}{8} E_{i}\left[-\frac{\left(y_{D}-y w_{D}\right)^{2}+\left(z_{D}-z_{w D}\right)^{2}}{4 t_{D}}\right]+2 \pi h_{D} \int_{t_{D_{e}}}^{t_{D}} s\left(x_{D}, \tau\right) \cdot s\left(y_{D}, \tau\right) \cdot s\left(z_{D}, \tau\right) d
\end{aligned}
$$

The dimensionless pressure derivative as a result of eqn. 7 will generate eqn. 8

$$
t_{D} p_{D}^{\prime}=\frac{\alpha h_{D}}{4} e^{-\frac{\left(y_{D}-y w_{D}\right)^{2}+\left(z_{D}-z_{w D}\right)^{2}}{4 t_{D}}}+2 \pi h_{D} t_{D} s\left(x_{D}, t_{D}\right) \cdot s\left(y_{D}, t_{D}\right) \cdot s\left(z_{D}, t_{D}\right)
$$

\subsubsection{Vertical Well Model}

For a single layer reservoir during early flow

$$
p_{D}=-E i\left(-\frac{r_{D}^{2}}{4 t_{D}}\right)
$$

Considering two flow periods

$$
P_{D}\left(x_{D}, y_{D}\right)=-\frac{1}{2} E i\left(\frac{r_{D}^{2}}{4 t_{D}}\right)+2 \pi h_{D} \int_{t D_{e}}^{t D} s\left(x_{D}, t_{D}\right) \cdot s\left(y_{D}, t_{D}\right) d t
$$

The dimensionless pressure derivatives from eqn. 10 will generate eqn. 11 below

$$
t_{D} p_{D}^{\prime}=\frac{1}{2} e^{-\frac{r_{D}^{2}}{4 t_{D}}}+2 \pi h_{D} t_{D} \cdot s\left(x_{D}, t_{D}\right) \cdot s\left(y_{D}, t_{D}\right)
$$

All the integrals were evaluated numerically according to Carnahan [10].

Table 1: Horizontal well $\left(x e_{D} y e_{D}, h_{D}\right):(20,20,5)$ and Vertical well $\left(x e_{D} y e_{D}\right):(20,20)$

Horizontal well $(20,20,5) \quad$ Vertical well $(20,20)$

\begin{tabular}{ccccc}
\hline$t_{D}$ & $P_{D}$ & $p_{D}^{\prime}$ & $P_{D}$ & $p_{D}^{\prime}$ \\
\hline 0.01 & $1.21 \mathrm{E}-02$ & 0.00104 & $2.68 \mathrm{E}-08$ & $1.06 \mathrm{E}-13$ \\
0.1 & 0.48 & 0.152 & $2.29 \mathrm{E}-04$ & $1.38 \mathrm{E}-08$ \\
1 & 1.5 & 0.45 & $1.88 \mathrm{E}-01$ & $9.41 \mathrm{E}-07$ \\
10 & 2.718 & 0.6 & $1.33 \mathrm{E}+00$ & $5.21 \mathrm{E}-03$ \\
100 & 3.869 & 0.6 & 2.49 & 0.5 \\
1000 & 5.02 & $7.36 \mathrm{E}-02$ & 2.84 & $7.14 \mathrm{E}-06$ \\
10000 & 5.02 & $3.66 \mathrm{E}-12$ & 2.84 & $1.85 \mathrm{E}-45$ \\
\hline
\end{tabular}

Table 2: Horizontal well $\left(x e_{D} y e_{D}, h_{D}\right):(50,50,10)$ and Vertical well $\left(x e_{D} y e_{D},\right):(50,50)$

\begin{tabular}{ccccc}
\hline \multicolumn{4}{c}{ Horizontal well $(50,50,10)$} & \multicolumn{3}{c}{ Vertical well $(50,50)$} \\
\hline$t_{D}$ & $P_{D}$ & $p_{D}^{\prime}$ & $P_{D}$ & $p_{D}^{\prime}$ \\
\hline 0.01 & $1.21 \mathrm{E}-02$ & 0.00104 & $2.68 \mathrm{E}-19$ & $1.06 \mathrm{E}-17$ \\
0.1 & 0.35 & 0.152 & $2.29 \mathrm{E}-03$ & $1.08 \mathrm{E}-02$ \\
1 & 1.6 & 1.04 & $3.13 \mathrm{E}-01$ & $3.41 \mathrm{E}-01$ \\
10 & 4 & 1.23 & $1.08 \mathrm{E}+00$ & $4.81 \mathrm{E}-01$ \\
100 & 7.18 & 1.2 & 2.49 & 0.5 \\
1000 & 10.6 & 1.2 & 3.64 & 0.5 \\
10000 & 12.4 & $2.32 \mathrm{E}-01$ & 3.76 & $7.34 \mathrm{E}-02$ \\
100000 & 12.4 & $1.30 \mathrm{E}-06$ & 3.76 & $1.30 \mathrm{E}-10$ \\
\hline
\end{tabular}

Table 3: Horizontal well $\left(x e_{D} y e_{D}, h_{D}\right):(50,50,20)$ and Vertical well $\left(x e_{D} y e_{D}\right):(50,50)$

\begin{tabular}{ccccc}
\hline & \multicolumn{3}{c}{ Horizontal well $(50,50,20)$} & \multicolumn{3}{c}{ Vertical well $(50,50)$} \\
\hline$t_{D}$ & $P_{D}$ & $p_{D}^{\prime}$ & $P_{D}$ & $p_{D}^{\prime}$ \\
\hline 0.01 & $1.21 \mathrm{E}-02$ & 0.00104 & $2.68 \mathrm{E}-19$ & $1.06 \mathrm{E}-17$ \\
0.1 & 0.48 & 0.152 & $2.29 \mathrm{E}-03$ & $1.08 \mathrm{E}-02$ \\
1 & 3 & 0.9 & $3.13 \mathrm{E}-01$ & $3.41 \mathrm{E}-01$ \\
10 & 7.5 & 1.7 & $1.34 \mathrm{E}+00$ & $4.81 \mathrm{E}-01$ \\
100 & 14.36 & 2.5 & 2.489 & 0.5 \\
1000 & 20.12 & 2.5 & 3.64 & 0.5 \\
10000 & 25 & $1.92 \mathrm{E}-01$ & 3.76 & $6.27 \mathrm{E}-02$ \\
100000 & 25 & $1.30 \mathrm{E}-05$ & 3.76 & $3.27 \mathrm{E}-09$ \\
\hline
\end{tabular}

\section{RESULTS AND DISCUSSION}

In comparison, From Tables 1 to table 3and also Figures 3 to 5 below; it can be observed that considering the same reservoir geometry; the horizontal well transients would travel farther through the reservoir than the vertical well transients at any given dimensionless time. In orders words, the pressure transient of the horizontal well is greater than that of the vertical well.

Reservoir geometry for Horizontal well $\left(x e_{D} y e_{D}, h_{D}\right)$ and Vertical well $=\left(x e_{D} y e_{D}\right)$

Given the same geometry, the horizontal well exhibits longer period of clean oil production than the vertical well derivative values from the Tables, in contrast to the early start of steady state on the vertical well 
dimensionless pressure. This means that vertical wells exhibit earlier arrival of edge water.

The horizontal well dimensionless pressure and pressure derivatives are strongly a function of three source functions $(\mathrm{x}, \mathrm{y}$ and $\mathrm{z})$ while the vertical well depends on two source functions ( $x$ and $y$ ).

Both wells models from Tables 1 to 3 , exhibit no slope when at the emergence of steady state, the dimensionless time of attainment of water breakthrough for both well models increase with increase in dimensionless reservoir area.

\section{CONCLUSION AND RECOMMENDATION}

The strength of both models during steady state is directly proportional to the pressure behaviour of the reservoirs. From the results, both models have the capacity to produce clean oil before experiencing water breakthrough is largely dependent on the reservoir areal extent. The period of radial flow is longer for horizontal well than vertical wells as shown by the pressure derivative curve.

1. Depending on the nature of the reservoir geometry especially for thin reservoir (low $h_{D}$ ), the drilling of an horizontal well is advised.

2. The larger the reservoir's external geometry, the longer the period available for clean oil production, the longer the time of attainment of steady state is longer for reservoir with large reservoir geometry.

3. For an efficient recovery plan, the drilling of a horizontal well is advised because it provides a longer period of clean oil production and subsequently delaying water breakthrough.

4. Pressure movement towards the external boundaries of the reservoir causes an increase in the dimensionless pressures

5. Horizontal well curves are characterized by higher dimensionless pressures than the vertical well of the same geometry.

\section{REFERENCES}

[1] Tarek, A. and Paul D. M. Advanced Reservoir Engineering, Elsevier (4 -151), 2005

[2] Ramey H. J. "Advances in Practical Well Test Analysis", SPE Stanford U. 44, 650, 1992,

[3] Matthews, C. S. and Russell, D.G."Pressure Buildup and Flowtest in Wells. Monograph Series", Society of Petroleum Engineers of AIME, Dallas, 1967.
[4] Muskat, M. "The Performance of Bottom Water-Drive Reservoirs", Trans. AIME, 170 , pp 81-111. 1947.

[5] Coats, K. H. "A Mathematical Model for Water Movement about Bottom Water-Drive Reservoirs", Trans. AIME, 225, 44-52, 1962.

[6] Gringarten, A. C. and Ramey, H. J. Jr. "The Use of Source and Green's Functions in Solving UnsteadyFlow Problems in Reservoirs," SPEJ , pp. 255 - 285, Oct. 1973.

[7] Ozkan, E. and R. Raghavan, "Performance of Horizontal Wells Subject to Bottom Water Drive," SPE Paper 18545, presented at the SPE Eastern Regional Meeting, Charleston, West Virginia, Nov. 2-4, 1988, pp. 375 383, 1990.

[8] Adewole, E. S. "The Use Of Source And Green's Functions To Derive Dimensionless Pressure And Dimensionless Pressure Derivative Distribution of A Two-Layered Reservoir Part I: A-Shaped Architecture", Journal of Mathematics and Technology, pp. 92 - 101, April 2010

[9] Eiroboyi, I. and Adewole, E.S "Type Curves for a Reservoir Subject to Active Bottom Water Drive", Advanced Materials Research, Trans Tech Publications, Switzerland. Vol. 824, 2013, pp 373378

[10] Carnahan, B. Luther, H.A. and Wilkes, J.O. "Applied Numerical Methods", John Wiley and Sons, 1969, p. 69140.

\section{Nomenclature}

$E_{i}=$ exponential integral function

$P_{D}=$ dimensionless pressure drop

$p_{D}^{\prime}=$ dimensionless pressure derivative drop

$r_{D}=$ dimensionless radius

$h_{D}=$ dimensionless height

$x_{D}=$ arbitrary dimensionless distance along the $\mathrm{x}$ axis

$y_{D}=$ arbitrary dimensionless distance along the $y$ axis

$x e_{D}=$ External reservoir radius along the $\mathrm{x}$ - axis

$y e_{D}=$ External reservoir radius along the $\mathrm{y}-$ axis

$r e_{D}=$ dimensionless reservoir radius

$t_{D}=$ dimensionless time

$t D_{e}=$ dimensionless time of attainment of steady state

$\mathbf{\tau}=$ dummy integration dimensionless time variable.

Eqn $=$ equation

\section{Superscript}

'= derivative

$\mathrm{D}=$ dimensionless .

$\mathrm{h}=$ horizontal .

$\Delta=$ change 